DOI: 10.21767/2471-9927.100036

\title{
Functioning of RNTCP in Kashmir Division of J\&K State (India)
}

Received: February 23, 2018; Accepted: March 23, 2018; Published: April 04, 2018

\section{Introduction}

\section{Problem Statement}

Tuberculosis (TB) is caused by microorganisms (Mycobacterium tuberculosis) that regularly influence the lungs. Tuberculosis is treatable and preventable is spread from individual to individual through the air. At the point when individuals with lung TB hack, sniffle or spit, they push the TB germs into the air. A man needs to breathe in just a couple of these germs to end up tainted. Around $33 \%$ of the total populace has dormant TB, which implies individuals have been tainted by TB microscopic organisms however are not (yet) sick with the malady and can't transmit the infection. Individuals tainted with TB microorganisms have a lifetime danger of falling sick with TB of $10 \%$. Be that as it may, people with bargained safe frameworks, for example, individuals living with HIV, lack of healthy sustenance or diabetes, or individuals who utilize tobacco, have a considerably higher danger of falling sick [1].

At the point when a man creates dynamic TB (infection), the indications (hack, fever, night sweats, weight reduction and so on.) might be mellow for a long time. This can prompt postponements in looking for care and results in the transmission of the microorganisms to others. Individual's sick with TB can contaminate up to 10-15 other individuals through close contact throughout a year [2]. Without legitimate treatment, up to $66 \%$ of individuals sick with TB will bite the dust [2]. Since 2000, 53 million lives have been spared through compelling determination and treatment. Dynamic, medicate touchy TB malady is treated with a standard half year course of 4 antimicrobial medications that are given data, supervision, and support to the patient by a wellbeing health care professional or prepared volunteer. Most by far of TB cases can be cured when prescriptions are given and taken appropriately.

The substantial scale usage of the Indian government's Revised National TB Control Program (RNTCP) (once in a while known as RNTCP 1) was begun in 1997 [3]. The RNTCP was then extended crosswise over India until the point when the whole country was shrouded by the RNTCP in March 2006. Right now, the RNTCP additionally ended up known as RNTCP II. RNTCP II was intended to solidify the additions accomplished in RNTCP I, and to start administrations to address TB/HIV, MDR-TB and to stretch out RNTCP to the private division [3]. RNTCP utilizes the World Health Organization (WHO) suggested Directly Observed Treatment
Sheikh Mohd Saleem*

Department of Community Medicine, Government Medical College, Srinagar, Jammu and Kashmir, India

\author{
*Corresponding author: \\ Sheikh Mohd Saleem \\ saleem.900@gmail.com \\ Department of Community Medicine, \\ Government Medical College, Srinagar, \\ Jammu and Kashmir, India.
}

Tel: $+91-7006806993$

Citation: Saleem SM (2018) Functioning of RNTCP in Kashmir Division of J\&K State (India). J Health Med Econ Vol.4 No.1:3

Short Course (DOTS) methodology [4] and reaches over a billion people in 632 locale/revealing units. The RNTCP is in charge of doing the Government of India five-year TB National Strategic Plans.

With the RNTCP both finding and treatment of TB are free. There is additionally, from a certain point of view, no sitting tight period for patients looking for treatment and TB drugs.

The underlying targets of the RNTCP in India were [5]:

- To accomplish and keep up a TB treatment achievement rate of no less than $85 \%$ among new sputum positive (NSP) patients.

- To accomplish and keep up the discovery of no less than $70 \%$ of the assessed new sputum constructive individuals in the group.

\section{Updated Technical and Operational Guidance}

In 2016 the RNTCP distributed updated specialized and operational direction. The new rules, the RNTCP Technical and Operational Guidelines for Tuberculosis Control in India 2016, did not supplant the past direction (the Standards of TB Care in India); however, they give refreshed proposals. They additionally make it totally certain that the direction applies to the private segment and also the general population segment [5]. The 
choice was likewise made to present a day by day TB treatment regimen. The new hostile to TB tranquilize bed aquiline for the treatment of medication safe TB was additionally to be made accessible at first in five states. For conclusion, the Go set up in excess of 600 CB-NAAT research facilities and improved their ability with profoundly delicate demonstrative administrations. CB-NAAT is the name given in India to Cartridge Based Nucleic Acid Amplification tests, for example, Genexpert and True Nat. Tuberculosis (TB) is a noteworthy general medical issue in India. The nation has the biggest number of TB cases on the planet-over a fourth of the worldwide TB and multidrug-safe TB (MDR-TB) trouble. In 2016, 2.79 million individuals turned out to be sick from TB, and 435,000 kicked the bucket from it. India has the best number of new instances of MDR-TB (counting rifampicin protection), with an expected 147,000 cases in 2016 [5].

There are in excess of 850,000 instances of TB every year in India that are either undetected and untreated or analysed and treated by private human services suppliers with possibly substandard medications and treatment regimens. Such medications and treatment regimens not just neglect to completely wipe out the TB microorganisms, however they additionally add to an expanding occurrence of medication safe TB (DR-TB), including both multidrug-safe TB, and broadly sedate safe TB (XDR-TB) $[3,5]$. India has the world's most noteworthy rate of TB, with 2.8 million cases yearly, and records for in excess of a fourth of the worldwide TB load. India likewise has the biggest weight of multi-tranquilize safe TB (MDR-TB) among all nations, with right around 150,000 cases each year [3,5]. TB asserts more than 435,000 Indian lives every year, which places TB among the best ten reasons for death in the nation. In acknowledgment of these disturbing measurements, USAID likewise declared another \$1 million push to convey more prominent attention to TB's shamewhich excessively influences ladies - to help Prime Minister Modi's definitive objective of securing a sans TB India by 2025. In India, as in numerous nations around the globe, individuals frequently fear how others will treat them on the off chance that they are determined to have TB. Women determined to have TB report their families, businesses and groups avoid and oppress them.

USAID has upheld the TB program of the Government of India (GOI) since 1998 and has contributed more than $\$ 140$ million to fortify the limit of national, State, and District-level TB programs [6]. USAID has additionally acquainted new apparatuses and methodologies with achieving, cure, and counteract TB in India effectively [6]. The present destinations of the USAID/India TB portfolio are to reinforce the discovery and treatment of TB, including an emphasis on tranquilizing safe strains; help the GOI to plan and actualize confirm based medications to achieve a TBFree India, and enhance persistent focused TB benefits in private supplier settings [6]. USAID/India's TB program is accomplishing its essential target of reinforcing the identification and treatment of TB, including drug-safe infection. Features from the program incorporate supplementing the nation's first national TB medicate protection review; steering and scaling-up the utilization of a fast symptomatic device, Genexpert, to analyses TB in youngsters, including multi-tranquilize safe strains; supporting the presentation of bed aquiline, the principal new medication affirmed to treat TB in over 40 years; and joining forces with the Bill and Melinda Gates Foundation and the India Knowledge Park to aid the advancement of the portable innovation, 99 DOTS, to enhance adherence treatment among patients [6].

\section{Organization Structure}

RNTCP Structure

The structure of RNTCP comprises of 5 levels

1. National

2. State

3. District

4. Sub - District

5. Peripheral health institutions.

\section{National central TB division}

- Programme Manager/DDG (TB)

- Plans/Supervises/Monitors/Evaluation

- National Committee on TB Diagnosis and Treatment

- National Laboratory Committee

- National Technical Working Group for TB/HIV

- National Institutes Etc.

\section{State TB cell: state TB officer}

- State TB Training and Demonstration Centre

- State drug store etc.

\section{District TB center}

District Tuberculosis Officer

- Drug resistant TB centers

\section{Sub-district tuberculosis unit}

(TU) 1 per 1.5 to 2.5 lac population Created for augmentation of peripheral level supervision- sub district supervisory unit

- Medical Officer-TB control (MO-TC): has overall responsibility of management of RNTCP assisted by STS and STLS

- Ensures regular supply of drugs in the sub-district

- Responsible for preparing quarterly reports on case finding, sputum conversion, results of treatment outcome

- Senior Treatment supervisor

- Senior TB Lab supervisor - one for 5 DMC's S/V

- TU is the nodal point for TB control activities in the subdistrict 


\section{Peripheral health institutions}

PHCs/ CHCs/ dispensaries/ hospitals within the district

- Designated Microscopy Centers (DMC)

- 1 per 1 lac population

- 1 per 0.5 lac population in tribal, hilly and difficult areas

- Medical Colleges, Corporate hospitals, ESI, Railways, NGOs, private hospitals $\bullet$ Treatment centers

- Responsible for accurate maintenance of TB register and timely submission of quarterly reports to the district level.

- DOTS Providers.

\section{Program Background}

The National Tuberculosis Program of India (NTP) was started in 1962 and was initially intended for domiciliary treatment, utilizing self-controlled standard medication regimens [6]. A survey of the program in 1992 presumed that the NTP was ineffectively overseen, insufficiently financed and couldn't accomplish TB control - Treatment achievement rates was unsatisfactorily low - Over- dependence on $\mathrm{X}$ - beam for determination - visit interfered with provisions of medications - Default rates stayed high - Death rates because of TB were still high $[3,5]$.

To beat these weaknesses, an overhauled technique to control TB was pilot-tried in 1993.Encouraged by the aftereffects of Pilot tests, the Revised National Tuberculosis Control Program (RNTCP) in 1997. This Revised National Tuberculosis Control Program (RNTCP) -Adopted the DOTS-system (Directly Observed Treatment, Short-course chemotherapy) [4]. During the principal stage, RNTCP accomplished nationwide scope in 2006. RNTCP entered stage II in 2007.To unite the increases and extend the administration's new activities: Wider joint effort with different divisions

- Standardized treatment and indicative office to all TB patients irrespective of the part (private or government)

- Improving access to minimized populace e.g. ghetto tenants and innate gatherings

\section{Accomplishments under RNTCP (Till 2016)}

- Covers the entire nation since 2006

- Treatment achievement rate achieved $88 \%$ of every 2015

- TB Death rate declined steeply from $25 \%$ (1998) to $4 \%$ (2015)

- CBNAAT accessible in all area level offices

Although India has figured out how proportional up essential TB benefits under RNTCP, the rate of decay is too ease back to meet the 2030 Sustainable Development Goals (SDG) and 2035 End TB targets.

New mediations are required to rush the rate of decay of rate of TB to more than $10-15 \%$ every year [7]. The endeavours for accomplishing this have arranged into the 'NSP for TB Elimination 2017-2025'

\section{Program Implementation Information}

In Kashmir RNTCP was begun from August-2004 and by 2005 every one of the regions were secured under the programme. PMDT (MDR Services) were begun 2007 in India while in Kashmir it began in 2012 Dynamic TB is the commonest crafty contamination among HIV tainted people and is the main source of death in PLWHA (People living with HIV Aids). TB-HIV Collaborative Activities are being executed in a joint effort with (National AIDS Control Program) to give TB treatment and administer to TBHIV patients. The essential motivation behind HIV TB Coordination is to guarantee ideal collaboration between the two projects for anticipation and control of the two sicknesses [8].

The usage rules were overhauled in 2016 as Technical and Operational Guidelines RNTCP 2016. Recording and announcing groups have been overhauled. All TB cases must be advised both openly and private area by uprightness of Government of India Order issued in May 2012. For this a case based, online TB notice framework (NIKSHAY) is set up in RNTCP.RNTCP is presently presenting Daily Treatment Regimen supplanting old discontinuous DOTS regimen where in the Anti-TB drugs should be given on regular routine to TB patients.

\section{Supervision and Monitoring at various levels}

State TB cell: It supervises monitors and analyses the Programme at Division level. State TB Demonstration cum Training Centre:

It is specialized unit under State TB Cell as per RNTCP for performing the following activities:

- Supervision.

- Trainings.

- Monitoring \& Evaluation.

- Quality Assurance of Sputum Microscopy.

- On-Site Evaluation.

- Panel Testing

- Diagnosis of Drug Resistant (TB).

At District Level the Program is managed by concerned District TB Officer. At TU Level the Program is being Supervised and Monitored by Medical Officer TB Center (MOTC) of concerned TU, who is helped by Sr. Treatment Supervisor (STS) and Sr. TB Laboratory Supervisor (STLS). 91 DMC $s$ are built up in Kashmir Province which are being given Binocular Microscopes and different coordination's (chemicals) and so on. At TU Level LED Microscopes have been provided by CTD Sputum Microscopy offices are accessible in all the DMCs.

With the end goal of RNTCP, a PHI is a Health office which is kept an eye on by a Medical Officer. At this level there are dispensaries, PHC's CHC's Referred Hospitals, real doctor's facilities, claim to fame centers or clinics (counting other Health offices), TB 
Hospitals and Medical universities inside the individual area. All the three Medical Colleges have been associated with the Program and for better outcomes; State Task Force and center advisory groups for every Medical College have been constituted who arrange with the District Tuberculosis Officer in running the Program in Medical Colleges.

\section{Supervision and Monitoring at various levels}

- MDR TB Diagnostic facilities are being expanded.

\section{References}

1 Reynolds NR (2009) cigarette smoking and HIV: more evidence for action. AIDS education and prevention : official publication of the International Society for AIDS Education 21: 106-121.

2 2. Pigrau-Serrallach $C$, Rodríguez-Pardo D (2013) Bone and joint tuberculosis. European Spine Journal 22: 556-566.

3 PTB guidelines 2017.

4 Moise L, Mcmurry J, Groot AS De (2009) Mycobacterium tuberculosis 1: $1219-1239$
- $\quad$ CBNAAT Machines have been installed and are functioning at:

1. District Anantnag

2. District Leh.

3. District Budgam.

4. District Baramulla.

5. District Kupwara.

5 RNTCP (2017) New Guidelines.

6 Sachdeva KS, Raizada N, Sreenivas A, van't Hoog AH, van den Hof $S$, et al. (2015) Use of Xpert MTB/RIF in Decentralized Public Health Settings and Its Effect on Pulmonary TB and DR-TB Case Finding in India. Chaturvedi V, editor.

7 Government of India, Home Central TB Division.

8 Government of Jammu \& Kashmir, Directorate of Health Services, Kashmir. 